\title{
Nuclear-encoded factors associated with the chloroplast transcription machinery of higher plants
}

\author{
Qing-Bo Yu ${ }^{1,2}$, Chao Huang ${ }^{1,2}$ and Zhong-Nan Yang ${ }^{1,2 *}$ \\ ' Department of Biology, College of Life and Environmental Sciences, Shanghai Normal University, Shanghai, China \\ ${ }^{2}$ Institute for Plant Gene Function, Department of Biology, Shanghai Normal University, Shanghai, China
}

\section{Edited by:}

Thomas Pfannschmidt, University Joseph Fourier Grenoble, France

Reviewed by:

Jin Chen, Michigan State University, USA

Takashi Shiina, Kyoto Prefectural

University, Japan

*Correspondence:

Zhong-Nan Yang, Department of Biology, College of Life and

Environmental Sciences, Shanghai Normal University, No.100,

Rd. Guilin, Shanghai 200234, China e-mail:znyang@shnu.edu.cn
Plastid transcription is crucial for plant growth and development. There exist two types of RNA polymerases in plastids: a nuclear-encoded RNA polymerase (NEP) and plastid-encoded RNA polymerase (PEP). PEP is the major RNA polymerase activity in chloroplast. Its core subunits are encoded by the plastid genome, and these are embedded into a larger complex of nuclear-encoded subunits. Biochemical and genetics analysis identified at least 12 proteins are tightly associated with the core subunit, while about 34 further proteins are associated more loosely generating larger complexes such as the transcriptionally active chromosome (TAC) or a part of the nucleoid. Domain analyses and functional investigations suggested that these nuclear-encoded factors may form several functional modules that mediate regulation of plastid gene expression by light, redox, phosphorylation, and heat stress. Genetic analyses also identified that some nuclear-encoded proteins in the chloroplast that are important for plastid gene expression, although a physical association with the transcriptional machinery is not observed. This covers several PPR proteins including CLB19, PDM1/SEL1, OTP70, and YS1 which are involved in the processing of transcripts for PEP core subunit as well as AtECB2, Prin2, SVR4-Like, and NARA5 that are also important for plastid gene expression, although their functions are unclear.

Keywords: plastid transcription, RNA polymerase, PEP, NEP, functional modules

\section{INTRODUCTION}

Plastids are specific organelles in plant and algal cells that are responsible for photosynthesis and some important metabolic pathways. They possess their own genetic material and are generally considered to be of endosymbiotic origin (McFadden and van Dooren, 2004). Similar to bacteria, the DNA is organized into dense particles, the nucleoids (Pfalz and Pfannschmidt, 2013). The genome size from plastids of vascular plants ranges from 120 to $180 \mathrm{kbp}$ and the encoded gene set is highly conserved (Sugiura, 1992). They can be categorized into three groups according to their molecular function of the encoded components: (1) Components of the plastid gene expression machinery (RNA polymerase, ribosomal proteins, tRNAs, and rRNAs); (2) Subunits of photosynthesis-related complexes (Rubisco, PSI, the cytochrome b6f complex, PSI, NAPH dehydrogenase, and ATP synthase), and (3) a few proteins involved in other processes (e.g., ClpP1 and YCF3) (Sugiura, 1992). The chloroplast proteome is estimated to be between 2100 and 3600 proteins (Leister, 2003). Most of the chloroplast proteins are encoded by the nuclear genome and are imported from the cytosol (Li and Chiu, 2010), due to the limited coding capacity of the chloroplast genome. However, chloroplast gene expression is still essential for the development of chloroplasts and the maintenance of chloroplast functions. It involves the action of numerous nuclear-encoded factors, besides proteins encoded by the plastome. Recently, proteomics data (Pfannschmidt et al., 2000; Ogrzewalla et al., 2002;
Suzuki et al., 2004; Pfalz et al., 2006; Steiner et al., 2011; Melonek et al., 2012) and genetic analysis (Chi et al., 2008; Ogawa et al., 2009; Wu and Zhang, 2010; Qiao et al., 2011, 2013; Kindgren et al., 2012; Pyo et al., 2013; Yu et al., 2013) identified that numerous nuclear-encoded proteins with various functions are associated with the transcriptional machinery and are involved in chloroplast gene expression. In this paper, we focused on these nuclear-encoded factors for chloroplast transcription.

\section{TWO TYPES OF PLASTID RNA POLYMERASES IN HIGHER PLANTS}

Plastid genes are transcribed by two RNA polymerases, the nuclear-encoded RNA polymerase (NEP) and the plastidencoded RNA polymerase (PEP). NEP is a phage-type RNA polymerase with a single subunit (Chang et al., 1999; LerbsMache, 2011). In Arabidopsis, the nuclear genome encodes three NEPs. RpoTp is targeted to chloroplast, RpoTm is targeted to mitochondria, and RpoTmp is dually targeted to both organelles (Hess and Borner, 1999). NEP is important for plant development. Inactivation of RpoTp results in defects in plastid gene expression and leaf development (Hricová et al., 2006; SwiateckaHagenbruch et al., 2008) while plants with inactivated RpoTmp exhibit several defects, including a plastid gene expression defect, delayed greening and growth retardation of leaves and roots (Courtois et al., 2007). The dysfunction of both NEPs resulted in seedling lethality at a very early developmental stage (Hricová et al., 2006). Although NEP is generally considered to be a single 
subunit RNA polymerase, recent biochemical analysis revealed that RPOTmp interacts with a thylakoid RING-H2 protein. This protein might mediate the fixation of RPOTmp to thylakoid membranes in order to regulate the transcription of the plastid rrn genes (Azevedo et al., 2008).

PEP is composed of four core subunits encoded by the genes $r p o A, r p o B, r p o C 1$, and $r p o C 2$ that are located on the plastid genome. PEP exhibits a certain sensitivity to inhibitors of bacterial transcription, such as tagetitoxin, and the group of rifampicin-related drugs, indicating a distinct degree of conservation of these eubacterial-type RNA polymerase during evolution (Liere et al., 2011). Like for bacterial RNA polymerases, the activity/specificity of the PEP core enzyme is regulated by sigma-like transcription factors that are encoded by the nuclear genome of higher plants. In Arabidopsis, there exist six chloroplast sigma factors (SIG1-SIG6). These sigma factors might have overlapping as well as specific functions for recognizing a specific set of promoters during chloroplast development (Schweer, 2010; Liere et al., 2011). Besides the sigma factors, however, the core subunits of PEP are associated also with additional proteins (see below) that mediate a number of additional functions to the PEP complex.

NEP and PEP play different roles in plastid gene transcription during plastid development and plant growth (Liere et al., 2011). Based on their transcription by the different RNA polymerases, plastid genes can be grouped into three classes (Hajdukiewicz et al., 1997; Ishizaki et al., 2005). Transcription of photosynthesisrelated genes (such as $p s b A, p s b D$, and $r b c L$ ) depend largely on PEP (class I), whereas a few house-keeping genes (mostly encoding components of the transcription/translation apparatus, such as $r p o B$ ) are exclusively transcribed by NEPs (class III). Most of plastid genes, however, are transcribed by both PEP and NEPs (class II). Generally, NEP is more active in the young, non-green tissues early in leaf development. It transcribes housekeeping genes including the four core subunits of PEP polymerase which primarily constitute the plastid gene expression machinery. Once PEP is formed in later developmental stages, it thereafter transcribes the photosynthesis-related genes (Hajdukiewicz et al., 1997; Lopez-Juez and Pyke, 2005; Schweer et al., 2010b) and plastid tRNAs (Williams-Carrier et al., 2014). In the mature chloroplast, the activity of NEP is barely detected, while PEP activity maintains high for chloroplast development and plant growth. Nevertheless, recent investigations demonstrated that both NEP and PEP are present in seeds, and PEP is also important for seed germination. This indicates that PEP exists also in non-photosynthetically active seed plastids (Demarsy et al., 2006).

\section{PEP IS ASSOCIATED WITH NUMEROUS NUCLEAR-ENCODED PROTEINS}

Early biochemical analysis demonstrated that two different forms of the PEP complex exist in higher plant, that is, PEP-A and PEP-B (Pfannschmidt and Link, 1994). PEP-B is composed only of the rpo core subunits and is present in both etioplasts and greening chloroplasts. During light-dependent chloroplast development, this PEP-B enzyme is reconfigured into an eukaryote-like enzyme complex, the PEP-A, by association of numerous proteins (Pfannschmidt and Link, 1997; Steiner et al., 2011; Pfalz and
Pfannschmidt, 2013). PEP-A is the major RNA polymerase in matured chloroplast of higher plant. Attempts have been focused on the isolation of the plastid RNA polymerase complex and its associated proteins for many years (Pfalz and Pfannschmidt, 2013). Biochemical analyses uncovered that the core rpo subunits of PEP are present in both the insoluble RNA polymerase preparation called transcriptionally active chromosome (TAC), and the soluble RNA polymerase preparation (sRNAP) (Krause and Krupinska, 2000; Pfalz et al., 2006; Melonek et al., 2012). The TAC fraction was isolated from lysed plastids through one or two gel filtration chromatography steps and subsequent ultracentrifugation, while the soluble RNA polymerase (sRNAP) is prepared from isolated and lysed plastids via several chromatographic purification steps without precipitation by centrifugation (Pfalz and Pfannschmidt, 2013). Based on gel filtration and mass spectrometry analysis from different organisms, including Nicotiana tabacum (Suzuki et al., 2004), spinach (Melonek et al., 2012), mustard (Sinapis alba) (Pfannschmidt et al., 2000; Pfalz et al., 2006; Steiner et al., 2011), and Arabidopsis (Pfalz et al., 2006) it is estimated that the TAC complex contains 43 nuclear-encoded proteins (Table 1). Ten proteins were reproducibly found to be tightly associated with PEP core subunits in mustard seedlings and, therefore, were named polymeraseassociated proteins (PAPs) (Steiner et al., 2011). The other proteins were found in the previous reported TAC complex and might represent more loosely attached components of the transcription machinery (Pfalz et al., 2006). Two TAC components, pTAC7 (Yu et al., 2013) and MurE-like (Garcia et al., 2008), were not identified as PAPs in mustard (Steiner et al., 2011), however, based on their mutant phenotype in T-DNA inactivation mutants of Arabidopsis these two proteins were proposed to be PAPs (Pfalz and Pfannschmidt, 2013). One essential common feature of all PAPs is that they are essential for PEP activity. The Arabidopsis knock-out lines for the corresponding genes show all an albino/ivory or pale-green phenotype with severe defects in chloroplast development and PEP-dependent transcription (Table 1) (Pfalz et al., 2006; Garcia et al., 2008; Myouga et al., 2008; Arsova et al., 2010; Schröter et al., 2010; Gao et al., 2011; Steiner et al., 2011; Gilkerson et al., 2012; Yagi et al., 2012; Yu et al., 2013). The phenotype of these PAP mutants is identical to that of rpo-gene knock-out mutants in tobacco (Allison et al., 1996; Hajdukiewicz et al., 1997; De Santis-Maclossek et al., 1999). In the knockout mutants of AtECB1/SVR4/MRL7 (Qiao et al., 2011; Yu et al., 2014), PEP-Related Development Arrested 1 (PRDA1) (Qiao et al., 2013), and Delayed Greening 1 (DG1) (Chi et al., 2008), the expression of PEP-dependent chloroplast genes is also severely reduced. These proteins have not been identified in PEP complex by previous proteomic analyses (Krause and Krupinska, 2000; Suzuki et al., 2004; Pfalz et al., 2006; Steiner et al., 2011). Nevertheless, they interacts with some members of the PEP/TAC complex (Chi et al., 2010; Qiao et al., 2011, 2013; Kindgren et al., 2012; Yu et al., 2014) and are either loosly or temporarily attached.

Based on proteomic analysis and protein interaction investigation, the TAC complex contains at least 50 proteins of which 46 are nuclear-encoded (Tables 1, 2). These nuclearencoded proteins can be classified into several groups including 


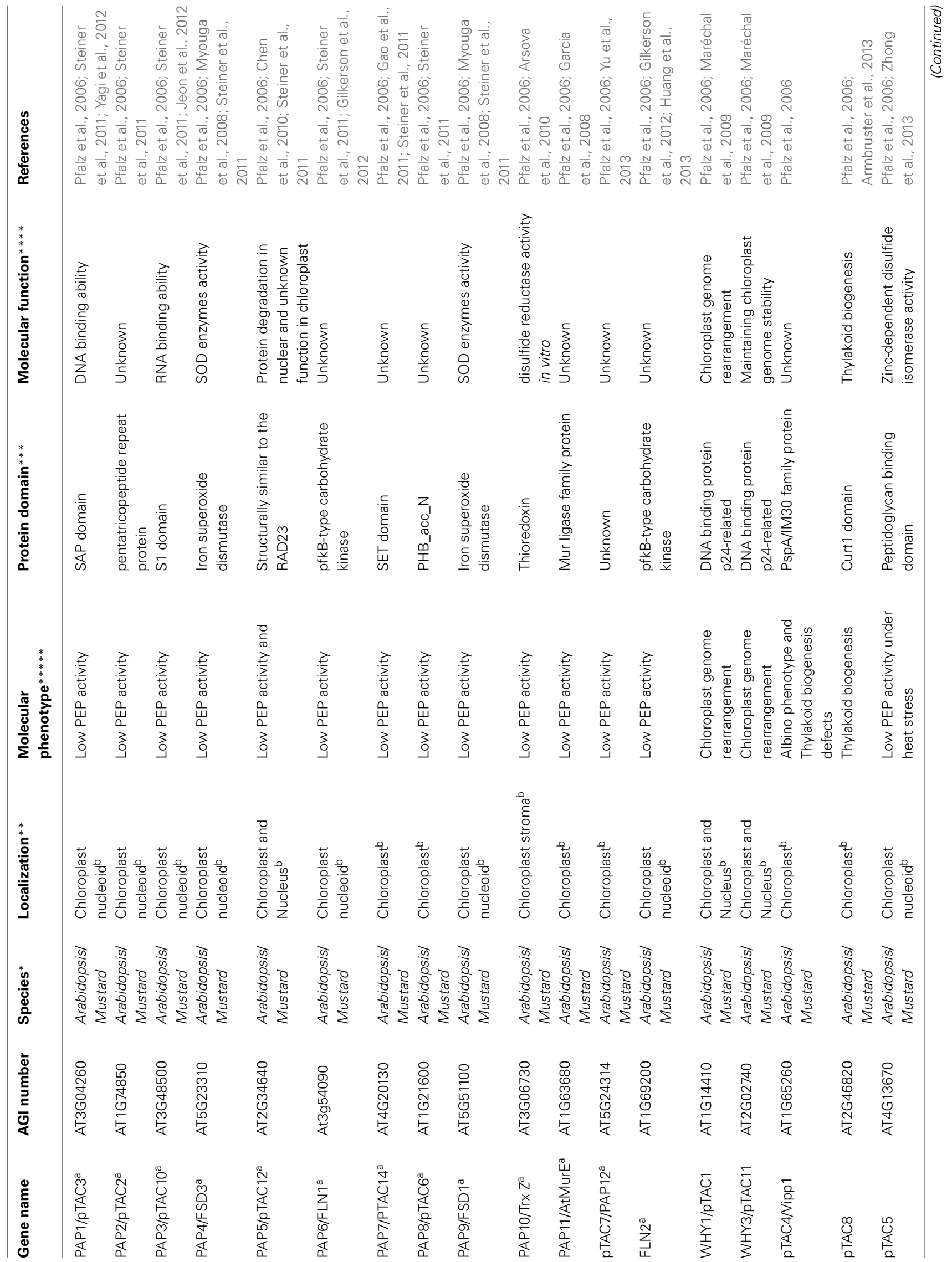




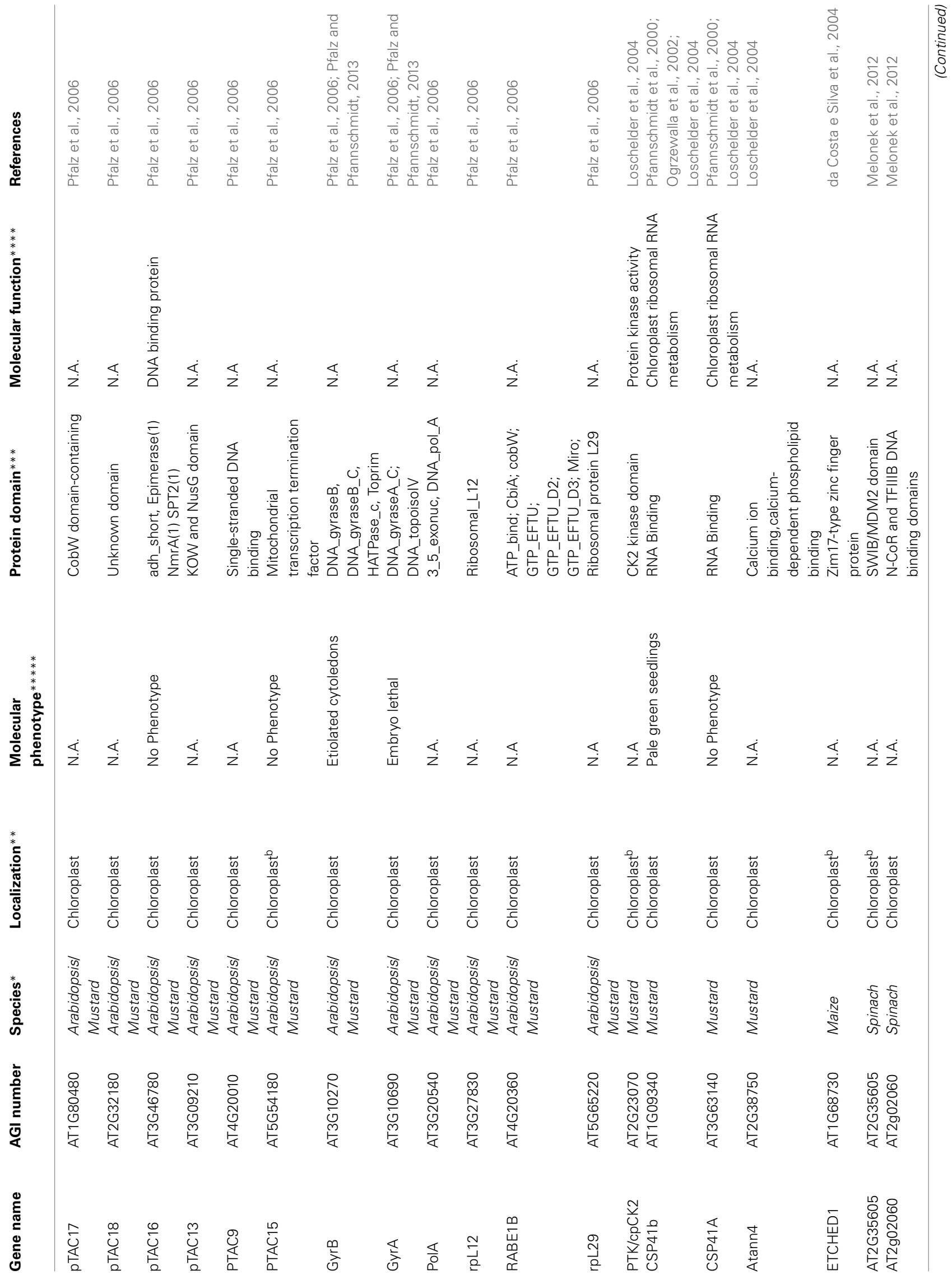




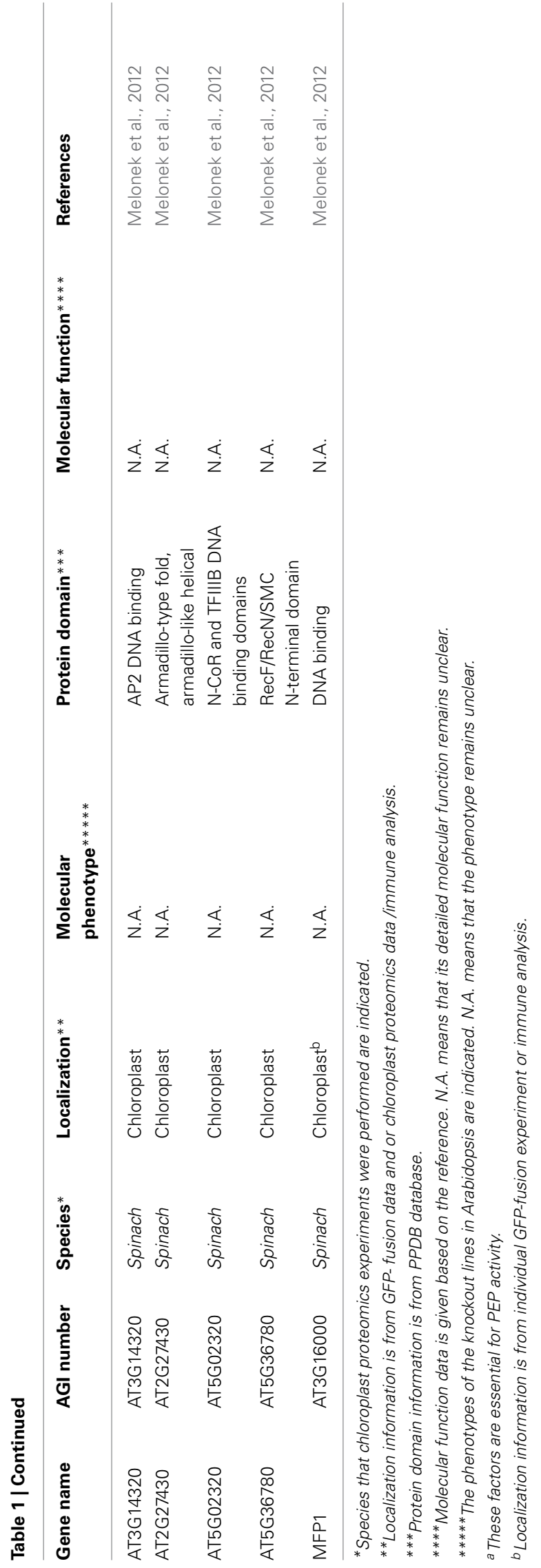

DNA/RNA binding proteins, thioredoxin proteins, kinases, ribosome proteins and proteins with unknown function (Table 1). Yeast two-hybrid and other biochemical assays revealed the relationship of some proteins in the PEP complex (Figure 1). The interactions between these PAPs are consistent with the biochemical experiments that identified these proteins in the PEP complex under the stringent condition (Steiner et al., 2011). Currently, proteins directly interacting with the PEP core subunits have not been identified in the PEP complex. Immunoprecipitation analysis demonstrated that pTAC3 is associated with the rpo subunits (Yagi et al., 2012). However, the direct interaction between PTAC3 and PEP core subunits has not been verified.

\section{PROTEINS IN THE PEP COMPLEX WITH DNA/RNA BINDING DOMAIN}

The eukaryotic transcriptional machinery consists of RNA polymerases and various DNA binding proteins, such as transcription factors. These DNA-binding proteins recognize the promoter to regulate downstream gene transcription. In the TAC complex, there are at least 14 proteins with DNA-binding domains (Table 1) (Pfalz et al., 2006; Steiner et al., 2011; Pfalz and Pfannschmidt, 2013). pTAC3 belongs to the SAP protein family. The ptac3 mutant exhibits an albino phenotype with reduced PEP-dependent plastid transcription. It is unclear yet if pTAC3 can bind to a specific DNA region in order to regulate plastid gene transcription (Yagi et al., 2012). pTAC6 is essential for chloroplast transcription (Pfalz et al., 2006) since the expression of the $p s b A$ gene was barely detectable in the ptac6 mutant, compared with that in ptac2 and ptac12 (Pfalz et al., 2006). It is likely that pTAC6 is a specific regulator for $p s b A$ (Pfalz et al., 2006), however, to date its function remains enigmatic. In bacteria, there exist two transcription termination mechanisms; Rho-independent transcription termination and Rho-dependent termination. The mitochondrial transcription termination factor (mTERF) family was identified to regulate mitochondrial gene expression including transcription termination (Kleine, 2012). pTAC15 is a member of the mTERF protein family (Pfalz et al., 2006). Whether it can terminate the transcription of PEP-dependent plastid genes needs to be verified.

The TAC complex contains at least six RNA-binding proteins including ZmWhyl, pTAC10, the elongation factor EF-Tu, and three ribosomal proteins, S3, L12-A, and L26 (Table 1). Whirly proteins belong to a small nuclear transcription factor family commonly found in plants. In Arabidopsis, pTAC1/AtWhyl and pTAC11/AtWhy3 can bind DNA (Xiong et al., 2009). They are required to maintain the stability of the plastid genome (Maréchal et al., 2009). The whirly 1 ortholog in maize (ZmWHY1/pTAC1) can bind both RNA and DNA, and co-immuno-precipitated with chloroplast RNA splicing 1 (CRS1) (Prikryl et al., 2008). pTAC10 contains a S1 domain and has RNA binding activity in tobacco (Jeon et al., 2012), and it may be one substrate of chloroplast-target casein kinase 2 (cpCK2) (Reiland et al., 2009). The phosphorylation of pTAC10 may affect its RNA binding. The detailed function of the elongation factor EF-Tu and the ribosomal proteins S3, L12-A, and L26 in chloroplast is not reported. The existence of these RNA-binding proteins, however, suggests that there exists a translation subdomainin the TAC/nucleoid. 


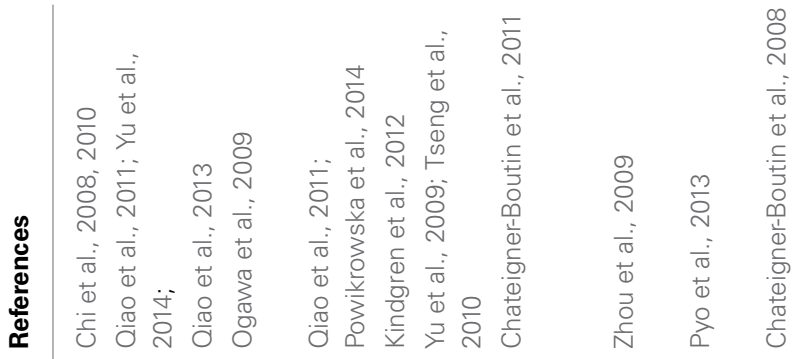

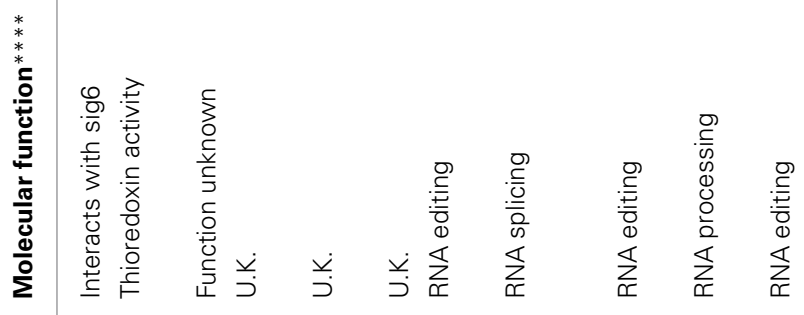

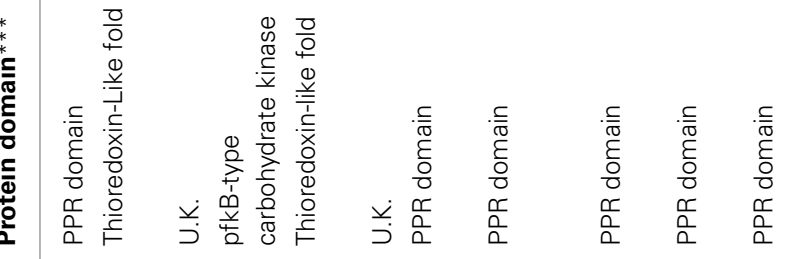

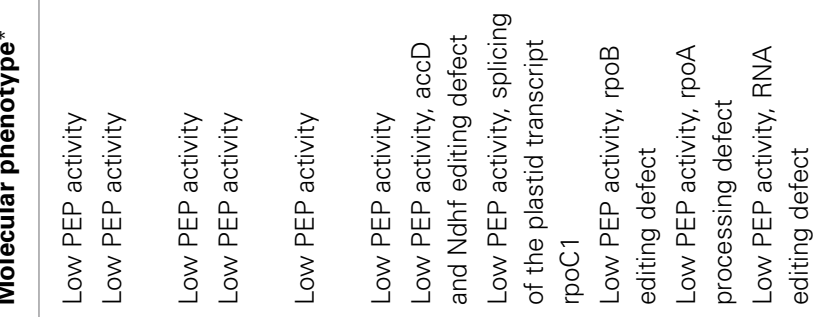

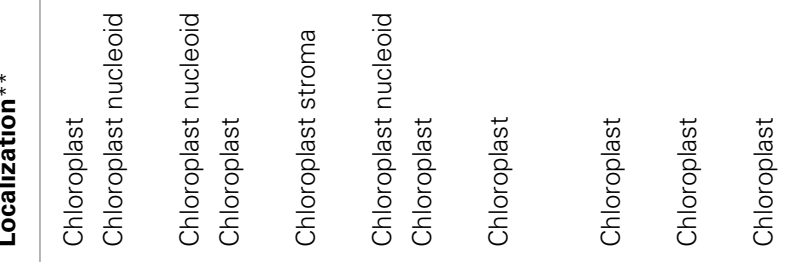

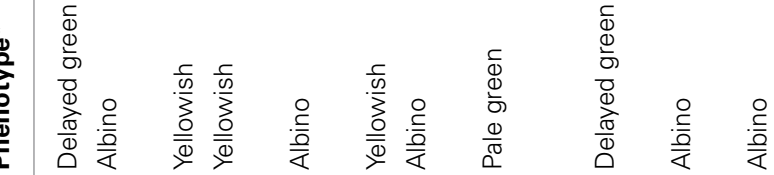

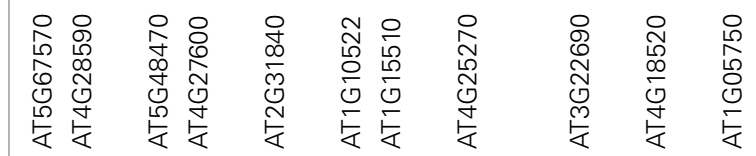

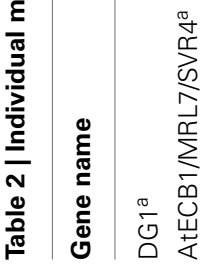

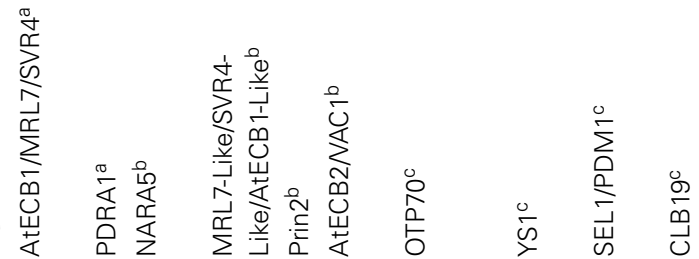

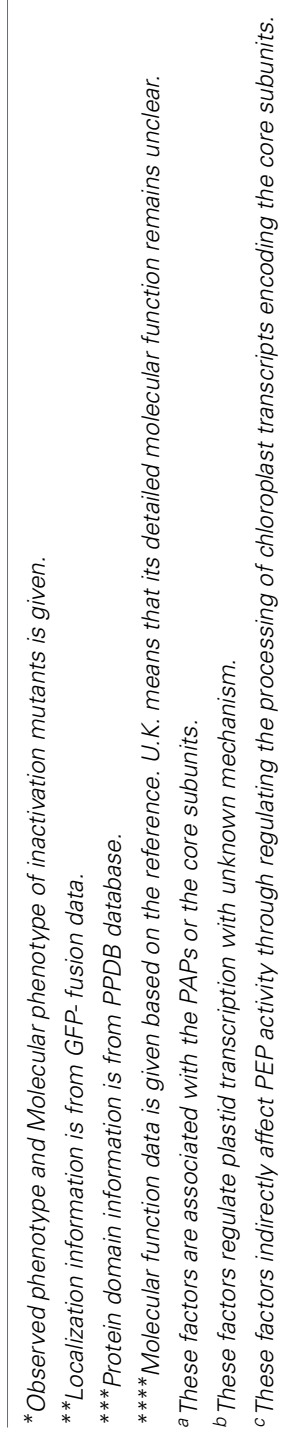




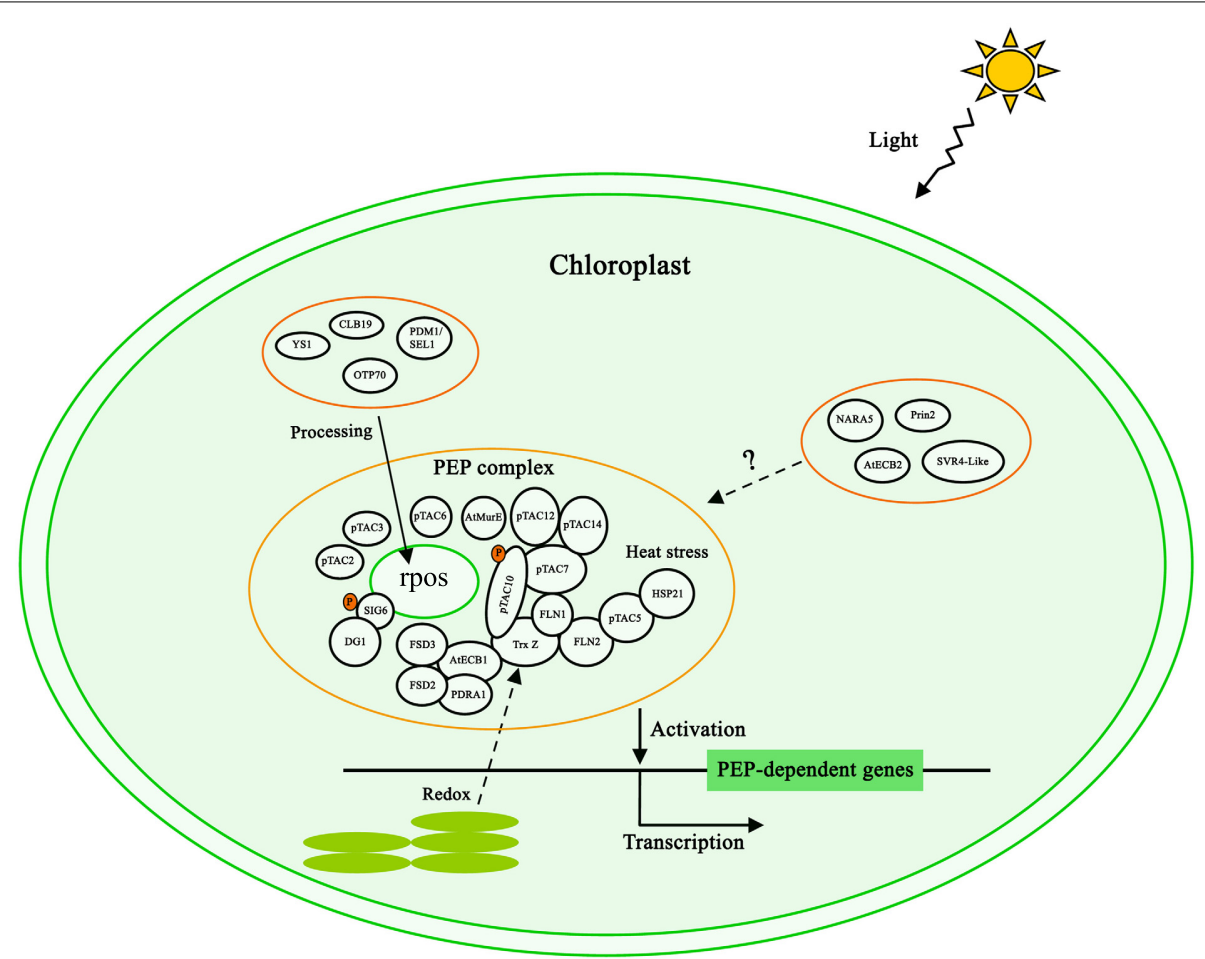

FIGURE 1 | Model of the PEP complex regulating chloroplast transcription. The reported interactions of PEP components are included. Light, redox status, phosphorylation and heat stress are involved in chloroplast transcription. Several PPR proteins including CLB19,
PDM1/SEL1, OTP70, and YS1 are involved in the processing of PEP core subunit transcripts to regulate PEP activity. AtECB2, Prin2, SVR4-Like and NARA5 are also important for plastid gene expression, but their mechanisms are unclear.

\section{CONNECTIONS OF REGULATORY MODULES WITH THE RNA POLYMERASE}

Light plays highly important roles in the regulation of plastid gene transcription. The majority of PAPs (Pfalz and Pfannschmidt, 2013) and most sigma factor genes of higher plants are lightinduced (Lerbs-Mache, 2011). Plastome-wide PEP-DNA association is also a light-dependent process (Finster et al., 2013). In plants, light plays an important role in almost every facet of plant growth and development through the action of photoreceptors. Interestingly, pTAC12 is an intrinsic subunit of the PEP complex (Pfalz et al., 2006; Steiner et al., 2011), but it was also identified as HEMERA and localized in both the nucleus and the chloroplast (Chen et al., 2010). pTAC12/HEMERA was considered as a proteolysis-related protein involved in phytochrome signaling in the nucleus (Chen et al., 2010). Its function in the PEP complex is unknown so far, but it was uncovered that pTAC12 interacts with pTAC14 in the yeast-two-hybrid system (Gao et al., 2011) suggesting that these two proteins might be also interaction partners in the native complex.

Chloroplasts are the site of photosynthesis that also produces reactive oxygen species (ROS). During photosynthesis, unbalanced excitation of the two photosystems affects the redox state of the electron transport chain which in turn serve as signals for plant acclimation responses. The PEP complex is a major target of such photosynthetic redox signals (Dietz and Pfannschmidt, 2011). Thioredoxin $\mathrm{z}(\operatorname{Tr} x \mathrm{Z})$ is a novel thioredoxin protein with disulfide reductase activity in vitro. It interacts with two fructokinase-like proteins FLN1 and FLN2 in the yeast two hybrid system and is also a component of the PEP complex (Pfalz et al., 2006; Steiner et al., 2011) (Figure 1). Trx-Z mediated redox change of FLN2 during light-dark transitions (Arsova et al., 2010). Recent studies identified AtECB1/MRL7 as a thioredoxinfold like protein with thioredoxin activity (Yu et al., 2014) that interacts with $\operatorname{Trx} \mathrm{Z}$ in the PEP complex (Powikrowska et al., 2014; Yu et al., 2014). These two proteins thus may form a functional module to mediate redox signaling from thylakoids toward the RNA polymerase but the functional details of these interactions are completely unknown. Further redox mediators might be Fe Superoxide Dismutase 2 (FSD2) and FSD3, two iron superoxide dismutases, and PRDA1 is a chloroplast protein without any known domain. prda 1 and $f_{s} d 2 f_{s} d 3$ knock out mutants are highly sensitive to oxidative stress (Myouga et al., 2008; Qiao et al., 2013). These proteins, therefore, may act as ROS scavengers in order to protect the PEP complex. The interactions between AtECB1 and PRDA1, FSD2, FSD3 suggest that the redox signaling pathway and ROS scavengers are eventually associated.

Protein phosphorylation is a very important post-translational modification in eukaryotic cells that regulates many cellular processes. In chloroplast, the phosphorylation of chloroplast proteins affects photosynthesis, metabolic functions and chloroplast transcription (Baginsky and Gruissem, 2009). The PEP complex appears to interact with a so-called plastid transcription kinase 
(PTK), named cpCK2 (Ogrzewalla et al., 2002). The Arabidopsis sigma factor 6 was reported to be phosphorylated by cpCK2 (Schweer et al., 2010a). Furthermore, pTAC5, pTAC10, and pTAC16, were also predicated to be phosphorylated by cpCK2 (Reiland et al., 2009). The enzyme activity of cpCK2 was inhibited by GSH, which suggests that cpCK2 is generally under SH-group redox regulation (Baginsky et al., 1999; Turkeri et al., 2012). Biochemical analyses of mustard seedlings during photosynthetic acclimation suggested that redox signals in chloroplasts are linked to chloroplast transcription via the combined action of phosphorylation and thiol-mediated regulation events (Steiner et al., 2009). Proteins related with phosphorylation and redox signaling are closely located in the PEP complex which is in agreement with the results of the physiological studies for plastid gene expression.

Heat stress is a major abiotic factor for plants, that leads to severe retardation in plant growth and development. To maintain the process of chloroplast transcription under heat stress and to support the survival of the plant, the chloroplast transcriptional machinery needs to deal with heat stress to a certain extent. The protein pTAC5 is a C4-type zinc finger DnaJ protein with disulfide isomerase activity. Its expression is induced by heat stress (Zhong et al., 2013) and, subsequently, pTAC5 and Heat Shock Protein 21 (HSP21) form a heterocomplex, although they are not PAP members of the PEP complex (Zhong et al., 2013). pTAC5 as well as HSP21 may protect chloroplast transcription under heat stress.

\section{OTHER NUCLEAR ENCODED FACTORS THAT REGULATE PEP ACTIVITY}

In addition to the intrinsic components of PEP complex, multiple additional factors were identified to regulate the processing of PEP core subunit transcripts and PEP activity by individual mutant analysis. Both Chloroplast Biogenesis19 (CLB19) (Chateigner-Boutin et al., 2008) and Pigment-Deficient Mutant 1(PDM1) (Wu and Zhang, 2010; Yin et al., 2012) genes encode pentatricopeptide repeat proteins. CLB19 is involved in the editing of the $r p o A$ transcript (Chateigner-Boutin et al., 2008), while $P D M 1$ is associated with $r p o A$ polycistronic for $r p o A$ cleavage (Wu and Zhang, 2010; Yin et al., 2012). Recent investigations demonstrated that PDM1/Seedling Lethal1 (SEL1) was also involved in accD RNA editing (Pyo et al., 2013). The PPR protein OTP70 was reported to affect the splicing of the $r p o C 1$ transcript (ChateignerBoutin et al., 2011). The gene Yellow Seedling 1 (YS1) encoding a PPR-DYW protein is required for editing of $r p o B$ transcripts (Zhou et al., 2009). The common feature of the Arabidopsis knockout lines for all these proteins is that the plastid expression pattern in these mutants is similar to that of rpo-gene knock-out mutants in tobacco (Chateigner-Boutin et al., 2008, 2011; Zhou et al., 2009; Wu and Zhang, 2010; Pyo et al., 2013).

Functional analyses revealed that several proteins including Arabidopsis Early Chloroplast Biogenesis 2 (AtECB2) (Yu et al., 2009), Plastid redox insensitive 2 (Prin2) (Kindgren et al., 2012), SVR4-Like (Powikrowska et al., 2014), and NARA5 (Ogawa et al., 2009), are also essential for PEP-dependent chloroplast transcription. However, it is unclear if they are directly associated with the PEP complex. AtECB2 encodes a pentatricopeptide repeat protein, and is involved in editing of $a c c D$ and $n d h F$ chloroplast transcripts (Yu et al., 2009; Tseng et al., 2010). The defective editing in ecb2 is unlikely to affect PEP-dependent plastid gene expression. How AtECB2 affects plastid gene expression is still unclear.
NARA5 encodes a chloroplast-localized phosphofructokinase B-type carbohydrate kinase family protein, which might be involved in massive expressions of plastid-encoded photosynthetic genes in Arabidopsis (Ogawa et al., 2009). The Prin2 is a small protein possibly involved in redox-mediated retrograde signaling in chloroplast (Kindgren et al., 2012) and the SVR4-like is a homolog of AtECB1/SVR4/MRL7, encoding a chloroplast protein essential for proper function of the chloroplast in Arabidopsis (Powikrowska et al., 2014). All these proteins may reversibly associate with the PEP complex but detailed studies are necessary to understand their functional roles and connections with the RNA polymerase. Alternatively, these proteins may act as signaling factors in order to mediate environmental stimuli and plastid gene expression.

\section{CONCLUDING REMARKS}

Plants grow under very different environment conditions and photosynthesis is the major function of chloroplast which is important for plant growth and development. Plastid gene expression is essential for chloroplast development and normal functions including photosynthesis. The PEP complex is the major RNA polymerase activity in mature chloroplasts. Proteomic and genetic analyses identified that at least 50 nuclearencoded proteins in higher plant are important for PEP dependent plastid gene expression. These proteins may form several functional modules within the nucleoid or TAC in order to mediate plastid gene expression in response to light, redox changes, phosphorylation and heat stress or to protect the PEP complex from ROS damage. The large number of nuclear-encoded proteins reveals the complexity of plastid gene expression and regulation that is greatly different from the gene expression in the nucleus or in prokaryotes. However, the current knowledge about plastid transcription is quite limited and the investigation of the relationship between transcription, post-transcriptional processing as well as translation in the nucleoid could provide novel insights into chloroplast gene expression.

\section{ACKNOWLEDGMENTS}

We are grateful to Prof. Thomas Pfannschmidt from Grenoble University for his help in editing the manuscript. This work was supported by grants from the National Science Foundation of China (Grant no. 31100965 and Grant no. 31370271).

\section{REFERENCES}

Allison, L. A., Simon, L. D., and Maliga, P. (1996). Deletion of rpoB reveals a second distinct transcription system in plastids of higher plants. EMBO J. 15, 2802-2809.

Armbruster, U., Labs, M., Pribil, M., Viola, S., Xu, W., Scharfenberg, M., et al. (2013). Arabidopsis CURVATURE THYLAKOID1 proteins modify thylakoid architecture by inducing membrane curvature. Plant Cell 25, 2661-2678. doi: 10.1105/tpc.113.113118

Arsova, B., Hoja, U., Wimmelbacher, M., Greiner, E., Ustün, S., Melzer, M., et al. (2010). Plastidial thioredoxin $\mathrm{z}$ interacts with two fructokinase-like proteins in a thiol-dependent manner: evidence for an essential role in chloroplast development in arabidopsis and nicotiana benthamiana. Plant Cell 22, 1498-1515. doi: 10.1105/tpc.109.071001

Azevedo, J., Courtois, F., Hakimi, M. A., Demarsy, E., Lagrange, T., Alcaraz, J. P., et al. (2008). Intraplastidial trafficking of a phage-type RNA polymerase is mediated by a thylakoid RING-H2 protein. Proc. Natl. Acad. Sci. U.S.A. 105, 9123-9128. doi: 10.1073/pnas.0800909105 
Baginsky, S., and Gruissem, W. (2009). The chloroplast kinase network: new insights from large-scale phosphoproteome profiling. Mol. Plant 2, 1141-1153. doi: $10.1093 / \mathrm{mp} / \mathrm{ssp} 058$

Baginsky, S., Tiller, K., Pfannschmidt, T., and Link, G. (1999). PTK, the chloroplast RNA polymerase-associated protein kinase from mustard (Sinapis alba), mediates redox control of plastid in vitro transcription. Plant Mol. Biol. 39, 1013-1023.

Chang, C. C., Sheen, J., Bligny, M., Niwa, Y., Lerbs-Mache, S., and Stern, D. B. (1999). Functional analysis of two maize cDNAs encoding T7-like RNA polymerases. Plant Cell 11, 911-926. doi: 10.1105/tpc.11.5.911

Chateigner-Boutin, A. L., des Francs-Small, C. C., Delannoy, E., Kahlau, S., Tanz, S. K., de Longevialle, A. F., et al. (2011). OTP70 is a pentatricopeptide repeat protein of the E subgroup involved in splicing of the plastid transcript rpoC1. Plant J. 65, 532-542. doi: 10.1111/j.1365-313X.2010.04441.x

Chateigner-Boutin, A. L., Ramos-Vega, M., Guevara-García, A., Andrés, C., de la Luz Gutiérrez-Navala Luz Gutiérrez-Navala Luz Gutiérrez-Nava, M., Cantero, A., et al. (2008). CLB19, a pentatricopeptide repeat protein required for editing of rpoA and clpP chloroplast transcripts. Plant J. 56, 590-602. doi: 10.1111/j.1365-313X.2008.03634.x

Chen, M., Galvão, R. M., Li, M., Burger, B., Bugea, J., Bolado, J., et al. (2010). Arabidopsis HEMERA/pTAC12 initiates photomorphogenesis by phytochromes. Cell 141, 1230-1240. doi: 10.1016/j.cell.2010.05.007

Chi, W., Ma, J., Zhang, D., Guo, J., Chen, F., Lu, C., et al. (2008). The pentratricopeptide repeat protein DELAYED GREENING1 is involved in the regulation of early chloroplast development and chloroplast gene expression in Arabidopsis. Plant Physiol. 147, 573-584. doi: 10.1104/pp.108.116194

Chi, W., Mao, J., Li, Q., Ji, D., Zou, M., Lu, C., et al. (2010). Interaction of the pentatricopeptide-repeat protein DELAYED GREENING 1 with sigma factor SIG6 in the regulation of chloroplast gene expression in Arabidopsis cotyledons. Plant J. 64, 14-25. doi: 10.1111/j.1365-313X.2010.04304.x

Courtois, F., Merendino, L., Demarsy, E., Mache, R., and Lerbs-Mache, S. (2007). Phage-type RNA polymerase RPOTmp transcribes the rrn operon from the PC promoter at early developmental stages in Arabidopsis. Plant Physiol. 145 712-721. doi: 10.1104/pp.107.103846

da Costa e Silva, O., Lorbiecke, R., Garg, P., Müller, L., Wassmann, M., Lauert, P., et al. (2004). The Etched 1 gene of Zea mays (L.) encodes a zinc ribbon protein that belongs to the transcriptionally active chromosome (TAC) of plastids and is similar to the transcription factor TFIIS. Plant J. 38, 923-939. doi: 10.1111/j.1365-313X.2004.02094.x

Demarsy, E., Courtois, F., Azevedo, J., Buhot, L., and Lerbs-Mache, S. (2006). Building up of the plastid transcriptional machinery during germination and early plant development. Plant Physiol. 142, 993-1003. doi: 10.1104/pp.106.085043

De Santis-MacIossek, G., Kofer, W., Bock, A., Schoch, S., Maier, R. M., Wanner, G., et al. (1999). Targeted disruption of the plastid RNA polymerase genes rpoA, B and C1: molecular biology, biochemistry and ultrastructure. Plant J. 18, 477-489. doi: 10.1046/j.1365-313X.1999.00473.x

Dietz, K., and Pfannschmidt, T. (2011). Novel regulators in photosynthetic redox control of plant metabolism and gene expression. Plant Physiol. 155, 1477-1585. doi: $10.1104 /$ pp. 110.170043

Finster, S., Eggert, E., Zoschke, R., Weihe, A., and Schmitz-Linneweber, C. (2013) Light-dependent, plastome-wide association of the plastid-encoded RNA polymerase with chloroplast DNA. Plant J. 76, 849-860. doi: 10.1111/tpj.12339

Gao, Z. P., Yu, Q. B., Zhao, T. T., Ma, Q., Chen, G. X., and Yang, Z. N. (2011). A functional component of the transcriptionally active chromosome complex, Arabidopsis pTAC14, interacts with pTAC12/HEMERA and regulates plastid gene expression. Plant Physiol. 157, 1733-1745. doi: 10.1104/pp.111. 184762

Garcia, M., Myouga, F., Takechi, K., Sato, H., Nabeshima, K., Nagata, N., et al. (2008). An Arabidopsis homolog of the bacterial peptidoglycan synthesis enzyme MurE has an essential role in chloroplast development. Plant J. 53, 924-934. doi: 10.1111/j.1365-313X.2007.03379.x

Gilkerson, J., Perez-Ruiz, J. M., Chory, J., and Callis, J. (2012). The plastid-localized pfkB-type carbohydrate kinases FRUCTOKINASE-LIKE 1 and 2 are essentia for growth and development of Arabidopsis thaliana. BMC Plant Biol. 12:102. doi: 10.1186/1471-2229-12-102

Hajdukiewicz, P. T., Allison, L. A., and Maliga, P. (1997). The two RNA polymerases encoded by the nuclear and the plastid compartments transcribe distinct groups of genes in tobacco plastids. EMBO J. 16, 4041-4048. doi: 10.1093/emboj/16.13.4041
Hess, W. R., and Borner, T. (1999). Organellar RNA polymerases of higher plants. Int. Rev. Cytol. 190, 1-59. doi: 10.1016/S0074-7696(08)62145-2

Hricová, A., Quesada, V., and Micol, J. L. (2006). The SCABRA3 nuclear gene encodes the plastid RpoTp RNA polymerase, which is required for chloroplast biogenesis and mesophyll cell proliferation in Arabidopsis. Plant Physiol. 141, 942-956. doi: 10.1104/pp.106.080069

Huang, C., Yu, Q. B., Lv, R. H., Yin, Q. Q., Chen, G. Y., Xu, L., et al. (2013). The reduced plastid-encoded polymerase-dependent plastid gene expression leads to the delayed greening of the Arabidopsis fln2 mutant. PLoS ONE 8:e73092. doi: 10.1371/journal.pone.0073092

Ishizaki, Y., Tsunoyama, Y., Hatano, K., Ando, K., Kato, K., Shinmyo, A., et al. (2005). A nuclear-encoded sigma factor, Arabidopsis SIG6, recognizes sigma70 type chloroplast promoters and regulates early chloroplast development in cotyledons. Plant J. 42, 133-144. doi: 10.1111/j.1365-313X.2005.02362.x

Jeon, Y., Jung, H. J., Kang, H., Park, Y. I., Lee, S. H., and Pai, H. S. (2012). S1 domain-containing STF modulates plastid transcription and chloroplast biogenesis in Nicotiana benthamiana. New Phytol. 193, 349-363. doi: 10.1111/j.1469-8137.2011.03941.x

Kindgren, P., Kremnev, D., Blanco, N. E., de Dios Barajas López, J., Fernández, A. P., Tellgren-Roth, C., et al. (2012). The plastid redox insensitive 2 mutant of Arabidopsis is impaired in PEP activity and high light-dependent plastid redox signalling to the nucleus. Plant J. 70, 279-291. doi: 10.1111/j.1365313X.2011.04865.x

Kleine, T. (2012). Arabidopsis thaliana mTERF proteins: evolution and functional classification. Front Plant Sci. 3:233. doi: 10.3389/fpls.2012.00233

Krause, K., and Krupinska, K. (2000). Molecular and functional properties of highly purified transcriptionally active chromosomes from spinach chloroplasts. Physiol. Plant 109, 188-195. doi: 10.1034/j.1399-3054.2000.100211.x

Leister, D. (2003). Chloroplast research in the genomic age. Trends Genet. 19, 47-57. doi: 10.1016/S0168-9525(02)00003-3

Lerbs-Mache, S. (2011). Function of plastid sigma factors in higher plants: regulation of gene expression or just preservation of constitutive transcription? Plant Mol. Biol. 76, 235-249. doi: 10.1007/s11103-010-9714-4

Li, H. M., and Chiu, C. C. (2010). Protein transport into chloroplasts. Annu. Rev. Plant Biol. 61, 157-180. doi: 10.1146/annurev-arplant-042809-112222

Liere, K., Weihe, A., and Börner, T. (2011). The transcription machineries of plant mitochondria and chloroplasts: composition, function, and regulation. J. Plant Physiol. 168, 1345-1360. doi: 10.1016/j.jplph.2011.01.005

Lopez-Juez, E., and Pyke, K. A. (2005). Plastids unleashed: their development and their integration in plant development. Int. J. Dev. Biol. 49, 557-577. doi: 10.1387/ijdb.051997el

Loschelder, H., Homann, A., Ogrzewalla, K., and Link, G. (2004). Proteomics-based sequence analysis of plant gene expression-the chloroplast transcription apparatus. Phytochemistry 65, 1785-1793. doi: 10.1016/j.phytochem.2004.04.034

Maréchal, A., Parent, J. S., Véronneau-Lafortune, F., Joyeux, A., Lang, B. F., and Brisson, N. (2009). Whirly proteins maintain plastid genome stability in Arabidopsis. Proc. Natl. Acad. Sci. U.S.A. 106, 14693-14698. doi: 10.1073/pnas.0901710106

McFadden, G. I., and van Dooren, G. G. (2004). Evolution: red algal genome affirms a common origin of all plastids. Curr Biol. 14, R514-R516. doi: 10.1016/i.cub.2004.06.041

Melonek, J., Matros, A., Trosch, M., Mock, H. P., and Krupinska, K. (2012). The core of chloroplastnucleoidscontainsarchitecturalSWIBdomainproteins. Plant Cell 24, 3060-3073. doi: 10.1105/tpc.112.099721

Myouga, F., Hosoda, C., Umezawa, T., Iizumi, H., Kuromori, T., Motohashi, R., et al. (2008). A heterocomplex of iron superoxide dismutases defends chloroplast nucleoids against oxidative stress and is essential for chloroplast development in Arabidopsis. Plant Cell 20, 3148-3162. doi: 10.1105/tpc.108.061341

Ogawa, T., Nishimura, K., Aoki, T., Takase, H., Tomizawa, K., Ashida, H., et al. (2009). A phosphofructokinase B-type carbohydrate kinase family protein, NARA5, for massive expressions of plastid-encoded photosynthetic genes in Arabidopsis. Plant Physiol. 151, 114-128. doi: 10.1104/pp.109.139683

Ogrzewalla, K., Piotrowski, M., Reinbothe, S., and Link, G. (2002). The plastid transcription kinase from mustard (Sinapis alba L.). A nuclear-encoded CK2-type chloroplast enzyme with redox-sensitive function. Eur. J. Biochem. 269, 3329-3337. doi: 10.1046/j.1432-1033.2002.03017_269_13.x

Pfalz, J., Liere, K., Kandlbinder, A., Dietz, K. J., and Oelmüller, R. (2006). pTAC2, -6 , and -12 are components of the transcriptionally active plastid chromosome that are required for plastid gene expression. Plant Cell 18, 176-197. doi: $10.1105 /$ tpc. 105.036392 
Pfalz, J., and Pfannschmidt, T. (2013). Essential nucleoid proteins in early chloroplast development. Trends Plant Sci. 18, 186-194. doi: 10.1016/j.tplants.2012.11.003

Pfannschmidt, T., and Link, G. (1994). Separation of two classes of plastid DNA-dependent RNA polymerases that are differentially expressed in mustard (Sinapis alba L.) seedlings. Plant Mol. Biol. 25, 69-81.

Pfannschmidt, T., and Link, G. (1997). The A and B forms of plastid DNAdependent RNA polymerase from mustard (Sinapis alba L.) transcribe the same genes in a different developmental context. Mol. Gen. Genet. 257, 35-44. doi: $10.1007 / \mathrm{s} 004380050621$

Pfannschmidt, T., Ogrzewalla, K., Baginsky, S., Sickmann, A., Meyer, H. E., and Link, G. (2000). The multisubunit chloroplast RNA polymerase A from mustard (Sinapis alba L.). Integration of a prokaryotic core into a larger complex with organelle-specific functions. Eur. J. Biochem. 267, 253-261. doi: 10.1046/j.14321327.2000.00991.x

Powikrowska, M., Khrouchtchova, A., Martens, H. J., Zygadlo-Nielsen, A., Melonek, J., Schulz, A., et al. (2014). SVR4 (suppressor of variegation 4) and SVR4-like: two proteins with a role in proper organization of the chloroplast genetic machinery. Physiol. Plant 150, 477-492. doi: 10.1111/ppl.12108

Prikryl, J., Watkins, K. P., Friso, G., van Wijk, K. J., and Barkan, A. (2008). A member of the Whirly family is a multifunctional RNA- and DNA-binding protein that is essential for chloroplast biogenesis. Nucleic Acids. Res. 36, 5152-5165. doi: 10.1093/nar/gkn492

Pyo, Y. J., Kwon, K. C., Kim, A., and Cho, M. H. (2013). Seedling Lethal1, a pentatricopeptide repeat protein lacking an E/E+ or DYW domain in Arabidopsis, is involved in plastid gene expression and early chloroplast development. Plant Physiol. 163, 1844-1858. doi: 10.1104/pp.113.227199

Qiao, J., Li, J., Chu, W., and Luo, M. (2013). PRDA1, a novel chloroplast nucleoid protein, is required for early chloroplast development and is involved in the regulation of plastid gene expression in Arabidopsis. Plant Cell Physiol. 54, 2071-2084. doi: 10.1093/pcp/pct148

Qiao, J. W., Ma, C. L., Wimmelbacher, M., Bornke, F. M., and Luo, M. Z. (2011). Two novel proteins, MRL7 and its paralog MRL-7, have essential but functionally distinvt roles in chloroplast development and are invovled in plastid gene expression regulation in Arabidopsis. Plant Cell Physiol. 52, 1017-1030. doi: $10.1093 / \mathrm{pcp} / \mathrm{pcr} 054$

Reiland, S., Messerli, G., Baerenfaller, K., Gerrits, B., Endler, A., Grossmann, J., et al. (2009). Large-scale Arabidopsis phosphoproteome profiling reveals novel chloroplast kinase substrates and phosphorylation networks. Plant Physiol. 150, 889-903. doi: 10.1104/pp.109.138677

Schröter, Y., Steiner, S., Matthäi, K., and Pfannschmidt, T. (2010). Analysis of oligomeric protein complexes in the chloroplast sub-proteome of nucleic acidbinding proteins from mustard reveals potential redox regulators of plastid gene expression. Proteomics 10, 2191-2204. doi: 10.1002/pmic.200900678

Schweer, J. (2010). Plant sigma factors come of age: flexible transcription factor network for regulated plastid gene expression. J. Endocyt. Cell Res. 20, 1-12.

Schweer, J., Türkeri, H., Kolpack, A., and Link, G. (2010b). Role and regulation of plastid sigma factors and their functional interactors during chloroplast transcription-recent lessons from Arabidopsis thaliana. Eur. J. Cell Biol. 89, 940-946. doi: 10.1016/j.ejcb.2010.06.016

Schweer, J., Turkeri, H., Link, B., and Link, G. (2010a). AtSIG6, a plastid sigma factor from Arabidopsis, reveals functional impact of cpCK2 phosphorylation. Plant J. 62, 192-202. doi: 10.1111/j.1365-313X.2010.04138.x

Steiner, S., Dietzel, L., Schroter, Y., Fey, V., Wagner, R., and Pfannschmidt, T. (2009). The role of phosphorylation in redox regulation of photosynthesis genes $p s a A$ and $p s b A$ during photosynthetic acclimation of mustard. Mol. Plant 2, 416-429. doi: $10.1093 / \mathrm{mp} / \mathrm{ssp} 007$

Steiner, S., Schröter, Y., Pfalz, J., and Pfannschmidt, T. (2011). Identification of essential subunits in the plastid-encoded RNA polymerase complex reveals building blocks for proper plastid development. Plant Physiol. 157, 1043-1055. doi: 10.1104/pp.111.184515

Sugiura, M. (1992). The chloroplast genome. Plant Mol. Biol. 19, 149-168. doi: $10.1007 / \mathrm{BF} 00015612$

Suzuki, J. Y., Ytterberg, A. J., Beardslee, T. A., Allison, L. A., Wijk, K. J., and Maliga, P. (2004). Affinity purification of the tobacco plastid RNA polymerase and in vitro reconstitution of the holoenzyme. Plant J. 40, 164-172. doi: 10.1111/j.1365-313X.2004.02195.x

Swiatecka-Hagenbruch, M., Emanuel, C., Hedtke, B., Liere, K., and Börner, T. (2008). Impaired function of the phage-type RNA polymerase RpoTp in transcription of chloroplast genes is compensated by a second phage-type RNA polymerase. Nucleic Acids. Res. 36, 785-792. doi: 10.1093/nar/gkm1111

Tseng, C. C., Sung, T. Y., Li, Y. C., Hsu, S. J., Lin, C. L., and Hsieh, M. H. (2010). Editing of $a c c D$ and $n d h F$ chloroplast transcripts is partially affected in the Arabidopsis vanilla creaml mutant. Plant Mol. Biol. 73, 309-323. doi: 10.1007/s11103-010-9616-5

Turkeri, H., Schweer, J., and Link, G. (2012). Phylogenetic and functional features of the plastid transcription kinase cpCK2 from Arabidopsis signify a role of cysteinyl $\mathrm{SH}$-groups in regulatory phosphorylation of plastid sigma factors. FEBS J. 279, 395-409. doi: 10.1111/j.1742-4658.2011.08433.x

Williams-Carrier, R., Zoschke, R., Belcher, S., Pfalz, J., and Barkan, A. (2014). A major role for the plastid-encoded RNA polymerase complex in the expression of plastid transfer RNAs. Plant Physiol. 164, 239-248. doi: 10.1104/pp.113.228726

$\mathrm{Wu}, \mathrm{H}$., and Zhang, L. (2010). The PPR protein PDM1 is involved in the processing of rpoA pre-mRNA in Arabidopsis thaliana. Chin Sci. Bull. 55, 3485-3489. doi: 10.1007/s11434-010-4040-4

Xiong, J. Y., Lai, C. X., Qu, Z., Yang, X. Y., Qin, X. H., and Liu, G. Q. (2009). Recruitment of AtWHY1 and AtWHY3 by a distal element upstream of the kinesin gene AtKP1 to mediate transcriptional repression. Plant Mol. Biol. 71, 437-449. doi: 10.1007/s11103-009-9533-7

Yagi, Y., Ishizaki, Y., Nakahira, Y., Tozawa, Y., and Shiina, T. (2012). Eukaryotic-type plastid nucleoid protein pTAC3 is essential for transcription by the bacterialtype plastid RNA polymerase. Proc. Natl. Acad. Sci. U.S.A. 109, 7541-7546. doi: 10.1073/pnas.1119403109

Yin, Q. Q., Cui, Y. L., Zhang, G. R., Zhang, H. D., Wang, X. M., and Yang, Z. N. (2012). The Arabidopsis pentatricopeptide repeat protein PDM1 is associated with the intergenic sequence of S11-rpoA for rpoA monocistronic RNA cleavage Chinese Sci. Bull. 57, 3452-3459. doi: 10.1007/s11434-012-5278-9

Yu, Q. B., Jiang, Y., Chong, K., and Yang, Z. N. (2009). AtECB2, a pentatricopeptide repeat protein, is required for chloroplast transcript accD RNA editing and early chloroplast biogenesis in Arabidopsis thaliana. Plant J. 59, 1011-1023. doi: 10.1111/j.1365-313X.2009.03930.x

Yu, Q. B., Lu, Y., Ma, Q., Zhao, T. T., Huang, C., Zhao, H. F., et al. (2013). TAC7, an essential component of the plastid transcriptionally active chromosome complex, interacts with FLN1, TAC10, TAC12 and TAC14 to regulate chloroplast gene expression in Arabidopsis thaliana. Physiol. Plant. 148, 408-421. doi: 10.1111/j.1399-3054.2012.01718.x

Yu, Q. B., Ma, Q., Kong, M. M., Zhao, T. T., Zhang, X. L., Zhou, Q., et al. (2014). AtECB1/MRL7, a thioredoxin-like fold protein with disulfide reductase activity, regulates chloroplast gene expression and chloroplast biogenesis in Arabidopsis thaliana. Mol. Plant 7, 206-217. doi: 10.1093/mp/ sst092

Zhong, L., Zhou, W., Wang, H., Ding, S., Lu, Q., Wen, X., et al. (2013). Chloroplast small heat shock protein HSP21 interacts with plastid nucleoid protein pTAC5 and is essential for chloroplast development in Arabidopsis under heat stress. Plant Cell 25, 2925-2943. doi: 10.1105/tpc.113.111229

Zhou, W., Cheng, Y., Yap, A., Chateigner-Boutin, A. L., Delannoy, E., Hammani, K., et al. (2009). The Arabidopsis gene YS1 encoding a DYW protein is required for editing of $\mathrm{rpoB}$ transcripts and the rapid development of chloroplasts during early growth. Plant J. 58, 82-96. doi: 10.1111/j.1365-313X.2008. 03766.x

Conflict of Interest Statement: The authors declare that the research was conducted in the absence of any commercial or financial relationships that could be construed as a potential conflict of interest.

Received: 31 March 2014; accepted: 14 June 2014; published online: 03 July 2014 Citation: Yu Q-B, Huang C and Yang Z-N (2014) Nuclear-encoded factors associated with the chloroplast transcription machinery of higher plants. Front. Plant Sci. 5:316. doi: $10.3389 / \mathrm{fpls} .2014 .00316$

This article was submitted to Plant Physiology, a section of the journal Frontiers in Plant Science.

Copyright (C) 2014 Yu, Huang and Yang. This is an open-access article distributed under the terms of the Creative Commons Attribution License (CC BY). The use, distribution or reproduction in other forums is permitted, provided the original author(s) or licensor are credited and that the original publication in this journal is cited, in accordance with accepted academic practice. No use, distribution or reproduction is permitted which does not comply with these terms. 